\title{
Hepatic Stellate Cells Support Hematopoiesis and are Liver-Resident Mesenchymal Stem Cells
}

\author{
Claus Kordes Iris Sawitza Silke Götze Dieter Häussinger \\ Clinic of Gastroenterology, Hepatology and Infectious Diseases, Heinrich Heine University, Düsseldorf
}

\section{Key Words}

Bone marrow mesenchymal stem cells - Extramedullary hematopoiesis - Fetal liver • Liver pericytes $\bullet$ Nestin $\cdot$ Hepatic stellate cells

\begin{abstract}
Background/Aims: Hematopoiesis can occur in the liver, when the bone marrow fails to provide an adequate environment for hematopoietic stem cells. Hepatic stellate cells possess characteristics of stem/progenitor cells, but their contribution to hematopoiesis is not known thus far. Methods: Isolated hepatic stellate cells from rats were characterized with respect to molecular markers of bone marrow mesenchymal stem cells (MSC) and treated with adipocyte or osteocyte differentiation media. Stellate cells of rats were further co-cultured with murine stem cell antigen- $1^{+}$hematopoietic stem cells selected by magnetic cell sorting. The expression of murine hematopoietic stem cell markers was analyzed by mouse specific quantitative PCR during co-culture. Hepatic stellate cells from eGFP+ ${ }^{+}$rats were transplanted into lethally irradiated wild type rats. Results: Desmin-expressing stellate cells were associated with hematopoietic sites in the fetal rat liver. Hepatic stellate cells expressed MSC markers and were able to differentiate into adipocytes and osteocytes in vitro. Stellate cells supported hematopoietic stem/progenitor cells during co-culture similar to bone marrow MSC, but failed to differentiate into blood cell lineages after transplantation. Conclusion: Hepatic stellate cells are liver-resident MSC and can fulfill typical functions of bone marrow MSC such as the differentiation into adipocytes or osteocytes and support of hematopoiesis.
\end{abstract}

Copyright (C) 2013 S. Karger AG, Basel

\section{Introduction}

In adult mammals, hematopoietic stem cells are localized in endosteal and perivascular regions of the bone marrow $[1,2]$. They are in close contact with osteoblasts, endothelial cells, nestin ${ }^{+}$mesenchymal stem cells (MSC) and sympathetic nerve fibers, which form a 


\section{Cellular Physiology and Biochemistry}

Cell Physiol Biochem 2013;31:290-304

DOI: $10.1159 / 000343368$

Published online: February 28, 2013

S. Karger AG, Base

www.karger.com/cpb

unique microenvironment called niche to support their maintenance and to control their recruitment, proliferation and development [1-4]. Nestin ${ }^{+}$MSC contribute to this niche through interaction with the sympathetic nervous system and release of cytokines such as angiopoietin 1 and their depletion rapidly reduces the hematopoietic stem cell content of the bone marrow [4]. Such an interaction may also be expected in the liver during fetal development or when the bone marrow fails to provide an adequate environment in diseases such as osteomyelofibrosis. In these cases the liver can provide an appropriate niche for migrating hematopoietic stem cells. First attempts were made to unravel a supportive function of fetal liver stromal cells such as the murine cell line AFT024 in maintaining primitive human hematopoietic cells [5, 6], but the liver cell type involved in blood formation support was not identified thus far. Desmin-expressing cells were found in close proximity to hematopoietic cells in the fetal liver [7] and hepatic stellate cells, which express desmin, were supposed to be involved in blood formation support [8], but experimental evidence was not provided yet. Stellate cells have characteristics of stem/progenitor cells $[9,10]$, which further suggests that they could play a role in extramedullary hematopoiesis. The aim of the present study was to unravel the role of hepatic stellate cells in this process. It was tested, whether stellate cells can support hematopoietic stem cells similar to bone marrow MSC. This was analyzed by co-culture experiments using hepatic stellate cells or bone marrow MSC of rats with murine stem cell antigen $1^{+}\left(\mathrm{SCA} 1^{+}\right)$hematopoietic stem cells. SCA1 signifies murine hematopoietic stem cells [11] and its expression decreases during their differentiation. In contrast to this, the transcription factor GATA1 is mainly expressed by cells of the hematopoietic system and increases during development of hematopoietic stem cells into primitive and definitive myeloid/erythroid cell lineages [12]. Thus, the expression of SCA1 and GATA1 can be used to identify early or lineage-restricted hematopoietic stem/ progenitor cells, respectively.

\section{Materials and Methods}

\section{Cell sources and cultures}

Hepatic stellate cells were isolated from adult male Wistar rats, which were obtained from the local breeding colony. Owing to their high lipid content, the stellate cells were enriched by density gradient centrifugation (8\% Nycodenz; Nycomed Pharma, Oslo, Norway) after enzymatic digestion of the liver essentially as described [13]. Isolated stellate cells (1 million per $6 \mathrm{~cm}$ culture dish) were cultured in Dulbecco's Modified Eagle Medium (DMEM; Gibco, Invitrogen, Karlsruhe, Germany) supplemented with $10 \%$ fetal calf serum (FCS Gold; PAA Laboratories, Pasching, Austria) and 1\% antibiotic/antimycotic solution (Gibco; 100x). Sinusoidal endothelial cells (SEC) and Kupffer cells (KC; macrophages of the liver) were isolated from rat liver by perfusion with collagenase CLS type I (Biochrom, Berlin, Germany) and pronase E (Merck) followed by density gradient centrifugation (20.5\% Nycodenz). SEC and KC were subsequently separated by centrifugal elutriation essentially as described [14]. SEC were cultured in endothelial cell growth medium (PromoCell, Heidelberg, Germany) on collagen type I coated culture dishes (Becton Dickinson Labware, Bedford, UK). KC were maintained in DMEM supplemented with 10\% FCS and $1 \%$ antibiotic/antimycotic solution. Parenchymal cells (PC) were isolated after digestion of rat liver by collagenase CLS type II (Biochrom) perfusion and subsequent centrifugation at $60 \mathrm{x} g$ [15]. About 1 million hepatic stellate cells, 6 million SEC, 4 million KC and 2 million PC were used per culture dish (6 $\mathrm{cm}$ diameter) to achieve equally distributed cell layers. Bone marrow MSC of Wistar rats were collected by flushing out the humeri. The bone marrow cell suspension was filtered and blood cell lineages were excluded by lineage depletion using antibodies against CD3 (\#MCA772F), CD45RA (\#MCA340FT), CD161 (\#MCA1427F; AbD Serotec, Oxford, UK) and CD11b (\#SM1764F; Acris, Herford, Germany) coupled to fluorescein isothiocyanate (FITC) using a FITC EasySep selection Kit (\#18558; Stem Cell Technologies, Vancouver, Canada) according to manufacturer's instructions. Remaining bone marrow cells were seeded on plastic dishes coated with collagen type 1 (BD Biosciences) and cultured in MSC expansion medium (\#CCM004; StemXVivo Mesenchymal Stem Cell Expansion Medium; R\&D Systems) until 70-80\% confluent cell monolayers were established. SCA1 ${ }^{+}$bone marrow cells were obtained from gently crushed humeri of 


\section{Cellular Physiology and Biochemistry}

Cell Physiol Biochem 2013;31:290-304

DOI: $10.1159 / 000343368$

Published online: February 28, 2013

Corger AG, Base

www.karger.com/cpb

the mouse strain C57BL/KaLwRij (Harlan, Horst, Netherlands). The cells from 8 humeri were first washed in phosphate buffered saline containing $0.5 \%$ ethylenediaminetetraacetic acid and $2 \%$ FCS. The cell suspension was filtered, adjusted to a volume of $2 \mathrm{ml}$ and SCA1-expressing cells were selected by magnetic cell sorting using the EasySep Mouse SCA1 Positive Selection Kit according to manufacturer's recommendations (\#18756; Stem Cell Technologies). The selected SCA1 ${ }^{+}$hematopoietic stem cells were added to $0.9 \%$ methylcellulose containing medium (\#U11-827; MethoStem; PAA Laboratories) prepared with Iscove's Modified Dulbecco's Medium (Gibco), 15\% FCS (FCS Gold; PAA Laboratories) and 1\% antibiotic/antimycotic solution (Gibco; 100x) (about 1 million cells per ml). In order to enhance cell colony formation $20 \mathrm{ng} / \mathrm{ml}$ of the cytokines interleukin-3 (IL-3), IL-6, and erythropoietin (EPO) were added (Sigma-Aldrich, St. Louis, MO, USA) as indicated. Equal volumes of the same $\mathrm{SCA}^{+}$cell suspension in methylcellulose medium were added to different cultures of hepatic cell types and bone marrow MSC. Hepatic stellate cells were cultured for 3-6 days, PC, SEC and KC for 1-2 days and bone marrow MSC for at least 14 days before the assays were initiated.

\section{Cell differentiation}

In vitro differentiation of rat hepatic stellate cells was performed with the Rat MSC Functional Identification Kit (\#SC020; R\&D Systems, Minneapolis, MN, USA) to test their differentiation into adipocytes. The development of isolated rat hepatic stellate cells into osteocytes was investigated with the OsteoPrime Induction Kit (\#U050-064; PAA). The stellate cells were treated with the differentiation media on glass cover slips for 14 and 21 days. The cells were finally fixed with $4 \%$ formalin for 15 minutes to detect fatty acid binding protein 4 (FABP4, \#962643) or with ice-cold methanol for 5 minutes to identify osteocalcin (\#962645) by immunofluorescence (R\&D Systems).

\section{Immunofluorescence}

Isolated cells or cryosections of the fetal (18-20 days post coitum) and adult rat liver were either fixed with ice-cold methanol for 5 minutes or formalin for 15 minutes and incubated with antibodies against $\alpha$-smooth muscle actin ( $\alpha$-SMA; \#IR611; Dako; Glostrup, Denmark), desmin (\#M0724; Dako), GATA1 (\#3535; Cell Signaling, Danvers, MA, USA), glial fibrillary acidic protein (GFAP; \#MAB3402; Millipore, Billerica, MA, USA), CD163 (\#MCA342R; AbD Serotec, Puchheim, Germany), keratin 18 (\#BM2275P; Acris Antibodies), rat endothelial cell antigen 1 (RECA1; \#sc-52665; Santa Cruz Biotechnology, Santa Cruz, CA, USA), plateletderived growth factor receptor- $\beta$ (PDGFR $\beta$; \#MA5-15143; Thermo Scientific, Rockford, IL, USA), CD146 (\#LS-C35841; LifeSpan BioSciences, Seattle, WA, USA) or nestin (\#sc-33677; Santa Cruz Biotechnology) for immunofluorescence. The primary antibodies were detected by cyanine dye 3 or fluorescein isothiocyanatelabelled antibodies against mouse, rabbit or goat immunoglobulins (Millipore). The cell nuclei were labelled by 4',6-diamidino-2-phenylindole (DAPI) through covering of cells and tissue sections with ProLong Gold (Molecular Probes, Invitrogen, Karlsruhe, Germany). The immunofluorescence pictures were made with the Olympus microscope IX50 (Olympus Deutschland GmbH, Hamburg, Germany) equipped with the filter sets U-MWU (BP330-385/420), U-MNIBA2 (BP470-490/515) and U-M41007A (BP525-560/594; Chroma Technologies, Bellows Falls, VT, USA) and a digital camera (DP71; Olympus Deutschland GmbH). Images series of immunofluorescence were made by the confocal laser-scanning microscope LSM 510 Meta using laser with $405 \mathrm{~nm}, 488 \mathrm{~nm}$ and $543 \mathrm{~nm}$ as well as the filter sets BP420-480, BP505-530 and BP560-615 (Carl Zeiss GmbH, Jena, Germany).

\section{Cytochemistry}

Alizarin Red solution (2 $\mathrm{g}$ in $100 \mathrm{ml}$ destilled water, filtered) was used to stain calcium deposition. Prior to this cultured cells on glass cover slips were fixed with ice-cold methanol for 5 minutes and finally stained with Alizarin Red solution for 2-5 minutes. The glass cover slips were removed from the dye solution and washed in acetone (20 dips), in acetone/xylol (equal volumes; 20 dips) and finally cleared in xylol.

\section{Western blot analysis}

Immunoblots of whole cell lysates were analyzed according to standard protocols. Primary antibodies against CD29 (\#AJ1408a; Abgent, Oxfordshire, UK), CD105 (\#05-1424; Millipore), GFAP, glutamine synthetase (GS; \#610517; BD Biosciences, Heidelberg, Germany), desmin, $\alpha$-SMA and $\gamma$-tubulin (\#T5326; Sigma-Aldrich) were used for Western blots. Secondary goat anti-mouse or anti-rabbit antibodies conjugated with horseradish peroxidase (Bio-Rad Laboratories, Munich, Germany) and enhanced chemoluminescence 
Table 1. Primer pairs for RT-PCR

\begin{tabular}{lllll}
\hline Gene & Forward Primer & Reverse Primer & bp & Accession No. \\
\hline rat $\alpha$-SMA & TGCTGGACTCTGGAGATG & GTGATCACCTGCCCATC & 292 & NM_031004 \\
rat $\beta$-actin & GCCCTAGACTTCGAGCAAGA & CAGTGAGGCCAGGATAGAGC & 390 & NM_031144 \\
rat CD29 & GAGGAATGTAACACGACTGCTG & ACTTCTTCTGTGAAGCCCAGAG & 564 & NM_017022 \\
rat CD73 & ACACTCTGGTTTCGAGATGGAT & ATTTCATCTGGGTGTCTGAGGT & 480 & NM_021576 \\
rat CD105 & ATCCCTCTGACCAGTGATGTCT & CTTTTTCCGAAGTGGTGGTAAG & 369 & NM_001010968 \\
rat CD146 & ATCTCTGTGTGGCATCTGTCC & ACTATCACAGCCACGATGACC & 487 & NM_023983 \\
rat CD271 & GCCTTGTGGCCTATATTGCTT & CTCGCTGCATAGACTCTCCAC & 458 & NM_012610 \\
rat COL1 $\alpha 2$ & ACCTCAGGGTGTCAAGGTG & CGGATTCCAATAGGACCAGA & 222 & NM_053356 \\
rat desmin & GACCTAGAGCGCAGAATTGAGT & GCCATCTCATCCTTTAGGTGTC & 476 & NM_022531 \\
rat FABP4 & TGGAAACTCGTCTCCAGTGAG & GTCACGCCTTTCATGACACAT & 347 & NM_053365 \\
rat GFAP & ACATCGAGATCGCCACCTAC & TCCACCGTCTTTACCACGAT & 163 & NM_017009 \\
rat nestin & GAGTGTCGCTTAGAGGTGCAA & TGTCACAGGAGTCTCAAGGGTA & 450 & NM_012987 \\
rat NG2 & CTGAGGTGAATGCTGGGAATA & GTCAGCTCAGATTGCAGGAAG & 394 & NM_031022 \\
rat osteocalcin & AGACAAGTCCCACACAGCAAC & TGGAGAGTAGCCAAAGCTGAA & 396 & NM_013414 \\
\hline
\end{tabular}

Table 2. Primer pairs for qPCR

\begin{tabular}{lllll}
\hline Gene & Forward Primer & Reverse Primer & bp & Accession No. \\
\hline mouse c-kit & TGGAGAAAACAGTGCAGTCCT & AACTCACCCACACGCATAGAC & 152 & NM_001122733 \\
mouse GATA1 & CAAACGACCACTACAACACTC & CCGCTCCAGCCAGATTCGAC & 190 & NM_008089 \\
mouse HPRT1 & CAGCGTTTCTGAGCCATTGCT & ATCCTCGGCATAATGATTAGGT & 226 & NM_013556 \\
mouse SCA1 & GGACACTTCTCACACTACAAAG & CCATACTTTCAATATTAGGAGGG & 254 & NM_010738 \\
mouse SLAMF1 & GCTGACACAGATATGAAGCAGA & CAGAATAAAGTCCAGAGAGCC & 203 & NM_013730 \\
rat IL-3 & TCAGATGCCCACCATTTACTC & GTTTGGACTTGATGTCCGTTG & 214 & NM_031513 \\
rat IL-6 & GGAGAGGAGACTTCACAGAGGA & CTCCAGAAGACCAGAGCAGATT & 266 & NM_012589 \\
rat EPO & CCTTGCTACTGATTCCTCTGG & AGCCTGTTCTTCCACCTTCAT & 218 & NM_017001 \\
rat G-CSF & CCTTGGAGCAAGTGAGGAAG & TTGGGGATACCCAGAGAGTG & 124 & NM_017104 \\
rat GM-CSF & GCCATTGAGTTTGGTGAGGT & TCCTAAATGACATGCGTGCT & 152 & XM_340799 \\
rat M-CSF & ATTCAGGATCCCCAGACCTC & ACTGGCAGTTCCACCTGTCTG & 199 & NM_023981 \\
rat RPS6 & GGAAGCGCAAGTCTGTCCGA & AGGTCCCAACCGACGAGGCA & 130 & NM_017160 \\
mouse/rat HPRT1 & AAGTGTTGGATACAGGCCAGA & GGCTTTGTACTTGGCTTTTCC & 145 & NM_012583 \\
\hline
\end{tabular}

detection reagents with chemoluminescence sensitive films (GE Healthcare Europe, Freiburg, Germany) were applied to visualize protein bands.

Reverse transcriptase polymerase chain reaction

First strand cDNA was made from 0.15 to $1 \mu \mathrm{g}$ total RNA per $20 \mu \mathrm{l}$ reaction volume (RevertAid H Minus First Strand cDNA Synthesis Kit; Fermentas, St. Leon-Rot, Germany). A standard protocol using the 2xPCR Master Mix (Fermentas), $0.8 \mu \mathrm{mol} / \mathrm{l}$ primers (Table 1) and 1 to $5 \mu \mathrm{l}$ template cDNA per $25 \mu \mathrm{l}$ reaction volume was applied to amplify PCR products in 35 cycles.

For quantitative real-time PCR (qPCR) $12.5 \mathrm{ng}$ cDNA per sample, $0.6 \mu \mathrm{mol} / \mathrm{l}$ primers (Table 2) and the SensiMix SYBR No-ROX Kit (Bioline, Luckenwalde, Germany) were used according to manufacturer's recommendations. A standard protocol with an initial denaturation of the cDNA at $95^{\circ} \mathrm{C}$, annealing at $58^{\circ} \mathrm{C}$ and elongation at $72^{\circ} \mathrm{C}$ was applied for 40 cycles using a TOptical cycler (Biometra, Göttingen, Germany). All samples were measured as triplicates and hypoxanthine-guanine phosphoribosyltransferase 1 (HPRT1) or ribosomal protein S6 (RPS6) served as reference genes for the normalization of values calculated by the $2^{-\Delta \Delta C t}$ method. Specific mouse primers were designed after comparison of mouse and rat mRNA sequences of HPRT1, SCA1, GATA1, signaling lymphocytic activation molecule F1 (SLAMF1) and c-kit. The forward primer used to detect mouse HPRT1 was placed in the untranslated region (UTR) and was not detectable in rats by BLAST analysis. The primers for mouse c-kit were both located in the UTR of this mRNA and exhibited no homology to rat sequences. To quantify mouse-specific SCA1, GATA1 and SLAMF1 mRNA by qPCR, each primer was designed with at least 5-7 mismatches compared to the corresponding rat mRNA sequence. The specificity of amplification products was verified by melting curves, the usage of no template controls (NTC) and agarose gel electrophoresis. 


\section{Cellular Physiology and Biochemistry}

Cell Physiol Biochem 2013;31:290-304

\begin{tabular}{l|l}
\hline DOI: $10.1159 / 000343368$ & (c) 2013 S. Karger AG, Basel
\end{tabular}

Published online: February 28, 2013

Fig. 1. Hepatic stellate cells are associated with sites of hematopoiesis in the fetal rat liver. Immunofluorescence of the hematopoietic marker GATA1 (red) and the stellate cell marker desmin (green; arrow) in the (A) adult and (B) fetal liver. (C) Threedimensional rendering of image series from fetal liver sections made by confocal laser-scanning microscopy (LSM). The sections were incubated with antibodies against GATA1 (red) and desmin (green). (D) Costaining of nestin (green; arrow) and GATA1 (red) on fetal liver sections. The cell nuclei were marked by DAPI (blue). All analysis were performed at least three times.

$A$

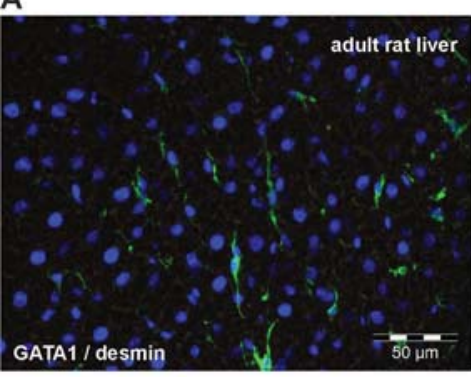

B

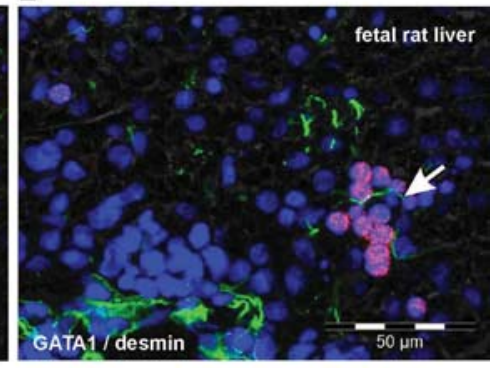

C

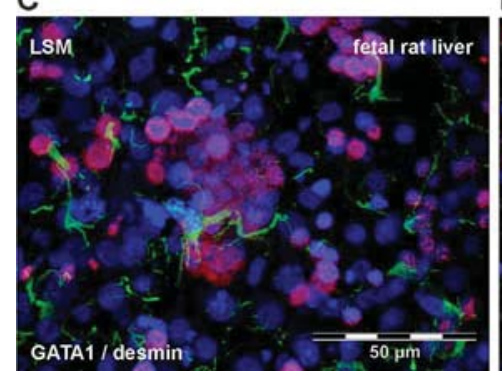

D

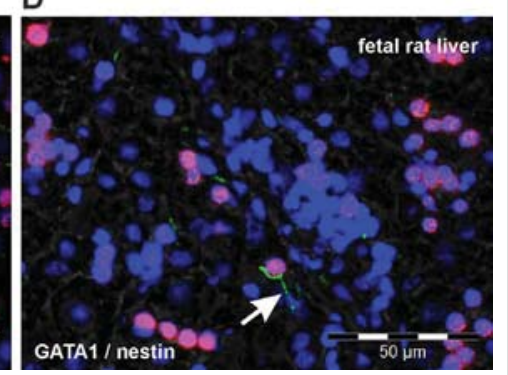

Transplantation of hepatic stellate cells into irradiated rats

Wild type male Wistar rats (210-260 g body weight) were irradiated with 9 gray (Gy) using a Cobalt-60 therapy unit (Philips X-ray \& Medical Equipment Division, Eindhoven, Netherlands). Immediately after lethal irradiation bone marrow cell preparations (200-300 $\mu \mathrm{l}$ of unsorted cell suspensions) or freshly isolated hepatic stellate cells from enhanced green fluorescent protein ${ }^{+}\left(\mathrm{eGFP}^{+}\right)$Wistar rats (average of 6 million cells), which express eGFP under the control of a chicken $\beta$-actin promoter (Wistar-TgN(CAG-GFP)184Ys; Rat Resource \& Research Center; University of Missouri, Columbia, MO, USA), were transplanted via tail vein injection. The irradiated rats were maintained in sterile cages with hoods, which were changed every second day. The animals received autoclaved food pellets and sterile filtered drinking water supplemented with antibiotics (10 mg enrofloxacine/Baytril per kg body weight and $30 \mathrm{ml}$ drinking water uptake per day; Bayer AG, Leverkusen, Germany) to prevent infections within the first weeks. The treatment with antibiotics was initiated one week before the animals were irradiated. Flow cytometry of eGFP-expressing cells obtained from blood and bone marrow of the irradiated host animals was performed with a BD FACSCanto flow cytometer (BD Biosciences; excitation $488 \mathrm{~nm}$, emission 530/30 nm) 8 weeks after irradiation. This experiment was approved by the local committee for animal protection and each animal received care according to the German animal welfare act.

\section{Statistics}

The qPCR values were analyzed with the Student's t-test and considered significant at $\mathrm{P}<0.05$. Results of at least 3 independent experiments were expressed as mean values and their variance was specified as standard error of mean.

\section{Results}

Stellate cells in the fetal liver

If hepatic stellate cells support blood formation, they should be detectable at sites of hematopoiesis in the fetal liver. The filamentous protein desmin was used to identify stellate cells in fetal and adult rat liver tissues (Fig. 1A-C). Desmin-expressing stellate cells were 


\section{Cellular Physiology and Biochemistry}

Cell Physiol Biochem 2013;31:290-304

DOI: 10.1159/000343368

www.karger.com/cpb

Kordes/Sawitza/Götze/Häussinger: Hepatic Stellate Cells Support Hematopoiesis
Fig. 2. Expression of MSC markers in isolated hepatic stellate cells. (A) RT-PCR analysis of MSC markers such as CD29, CD73, CD105, CD146, CD271, nestin and NG2 in hepatic stellate cells and bone marrow MSC of rats, which were cultured for 1 (1d) and 7 days (7d). Indicators of myofibroblast-like cells such as $\alpha$-SMA and COL $1 \alpha 2$ were also analyzed. Immunofluorescence of the stellate cell markers (B) GFAP and (C) desmin as well as the MSC markers (D) nestin, (E) CD146 and (F) PDGFR $\beta$ (red) in hepatic stellate cells, which were cultured for 1 and 7 days (inserts). (G) Western blot analysis of MSC (CD29, CD105, CD146) and stellate cell markers (GFAP, glutamine synthetase/ GS, desmin, $\alpha$-SMA) in freshly isolated (1d) and cultured (7d) hepatic stellate cells as well as cultured bone marrow MSC. The protein $\gamma$-tubulin served as a control. All analysis were performed at least three times.
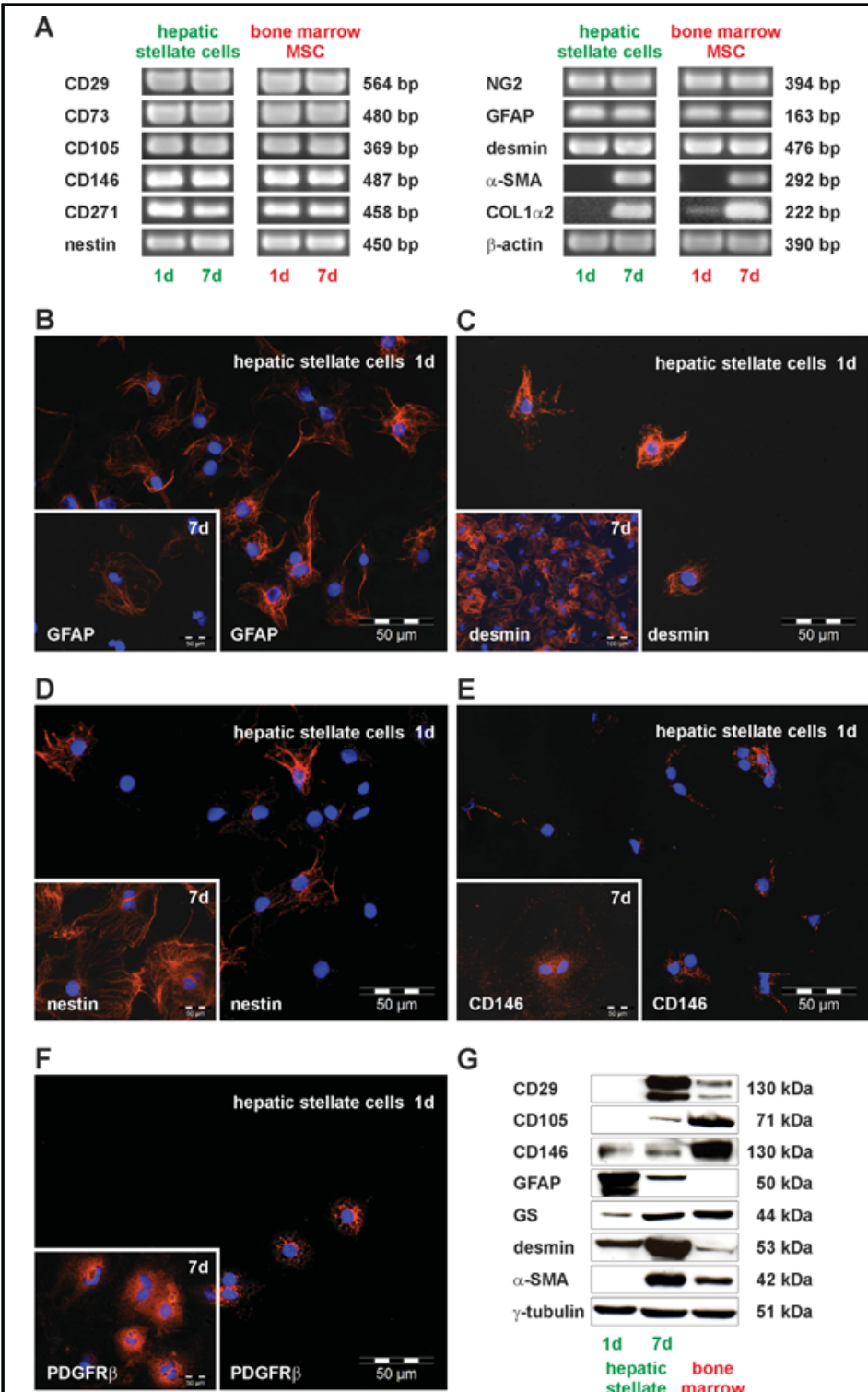

G

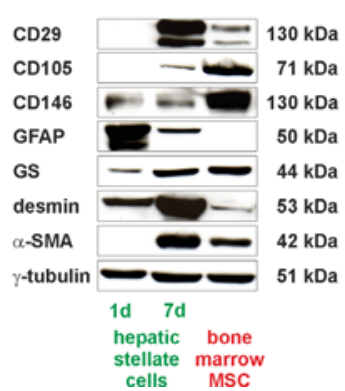

detected in close proximity to developing myeloid/erythroid progenitor cells, which were identified by nuclear GATA1 staining (Fig. 1C,B). Nestin-expressing stellate cells were also found to be associated with GATA1 ${ }^{+}$hematopoietic precursor cells in the fetal rat liver (Fig. 1D).

Comparison of hepatic stellate cells and bone marrow MSC

To verify the hypothesis that hepatic stellate cells could represent supportive stromal cells for hematopoietic stem cells their expression profile was analyzed by RT-PCR and compared with bone marrow MSC. Molecular markers of MSC such as CD29, CD73, CD105, CD146, CD271, nestin and nerve/glial antigen 2 (NG2) were congruently expressed by bone marrow MSC and freshly isolated (1 day) as well as cultured (7 days) hepatic stellate cells. Typical stellate cell markers such as GFAP and desmin were also detected at the mRNA level in both hepatic stellate cells and bone marrow MSC. Moreover, the expression of the myofibroblast markers $\alpha$-SMA and collagen type $1 \alpha 2$ chain (COL1 $\alpha 2$ ) was induced in hepatic stellate cells and bone marrow MSC during culture, demonstrating remarkable similarities between both cell populations (Fig. 2A). 


\section{Cellular Physiology and Biochemistry}

Cell Physiol Biochem 2013;31:290-304
Fig. 3. Differentiation of isolated rat hepatic stellate cells into adipocytes and osteocytes in vitro. Immunofluorescence analysis of (A) FABP4 and (B) osteocalcin (red) on freshly isolated hepatic stellate cells, which were cultured for 1 day (1d) $[\mathrm{n}=3]$. Cultured hepatic stellate cells were treated with $(\mathrm{C})$ control medium (DMEM supplemented with 10\% FCS) or (D) a medium favoring the differentiation of MSC into adipocytes for 21 days. (C, D) The synthesis of the adipocyte marker FABP4 (red) was investigated by immunofluorescence (insert, overview) [n=3]. The expression of the osteoblast marker osteocalcin (red) was determined by immunofluorescence in hepatic stellate cells, which were cultured with (E) control medium (DMEM supplemented with $10 \%$ FCS) or (F) osteocyte differentiation medium for 21 days (insert, overview) [n $=4]$. The cell nuclei were labeled by DAPI staining (blue). RT-PCR analysis of FABP4 and osteocalcin after treatment of isolated hepatic stellate cells with $(\mathrm{G})$ adipocyte or $(\mathrm{H})$ osteocyte differentiation media for 21 days $[\mathrm{n}=3]$. The control medium consists of DMEM supplemented with $10 \%$ FCS. The $\beta$-actin expression served as a control.
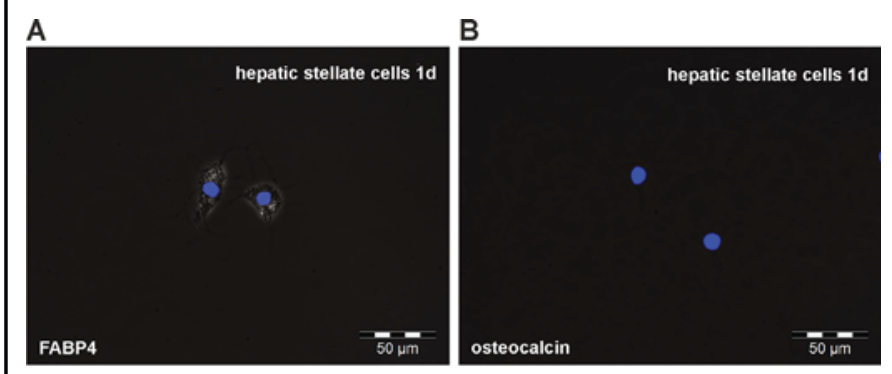

C

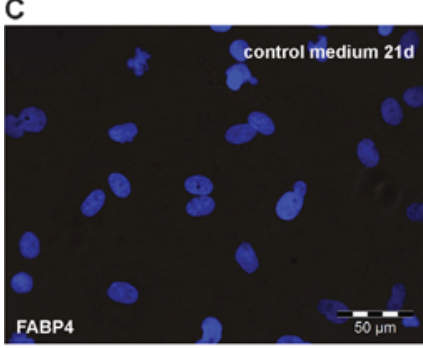

D

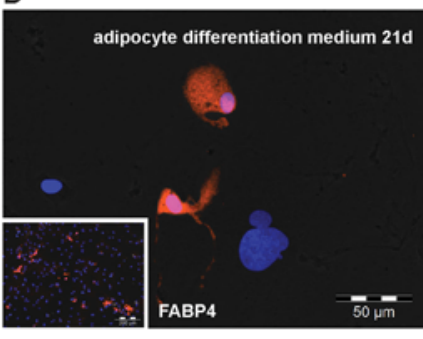

E

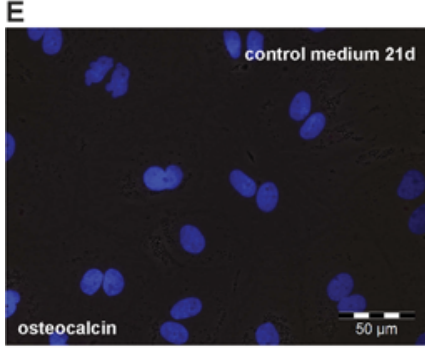

F

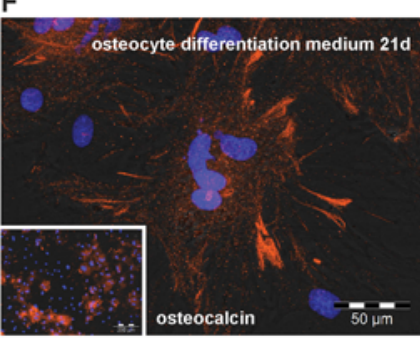

G

$\mathrm{H}$

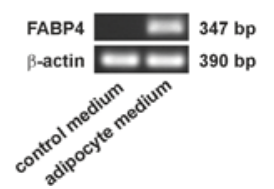

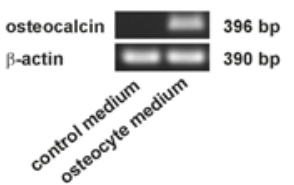

Although the mRNA of GFAP was detected in isolated bone marrow MSC, only hepatic stellate cells showed GFAP at the protein level. GFAP decreased during culture in hepatic stellate cells as demonstrated here after 7 days (Fig. 2B,G), whereas the expression of desmin and nestin increased with time in culture (Fig. 2C,D,G). The MSC markers CD146 and PDGFR $\beta$ were synthesized by freshly isolated and cultured hepatic stellate cells (Fig. 2E,F,G). Other proteins associated with MSC such as CD29 and CD105 were elevated during culture of hepatic stellate cells as demonstrated by Western blot analysis (Fig. 2G), suggesting that stellate cells acquire additional MSC characteristics during their activation. Cultured MSC, in turn, expressed markers of activated stellate cells like glutamine synthetase (GS), desmin and $\alpha$-SMA (Fig. 2G).

\section{Hepatic stellate cells can differentiate into adipocytes and osteocytes}

Due to the lack of a universal molecular signature of MSC, this cell type is usually characterized by its function or differentiation potential. Since MSC can develop into adipocytes and osteocytes, this was also tested with isolated rat hepatic stellate cells. Quiescent stellate cells did not express fatty acid binding protein 4 (FABP4) and osteocalcin (Fig. 3A,B), which are molecular markers of adipocytes and osteocytes, respectively. After treatment of cultured hepatic stellate cells with different commercially available differentiation media 
Fig. 4. Differentiation of rat hepatic stellate cells into adipocytes and osteocytes in vitro. Hepatic stellate cells cultured for 7 days were treated for additional 21 days with (A) control medium (DMEM supplemented with $10 \%$ FCS) or (B) adipocyte differentiation medium. (A) The vitamin A content of stellate cells was investigated by UV light excitation of retinoids (blue) in freshly isolated (1d, insert) and cultured (21d) hepatic stellate cells under control conditions. (B) Culture-activated hepatic stellate cells were treated with adipocyte differentiation medium for 21 days (21d).
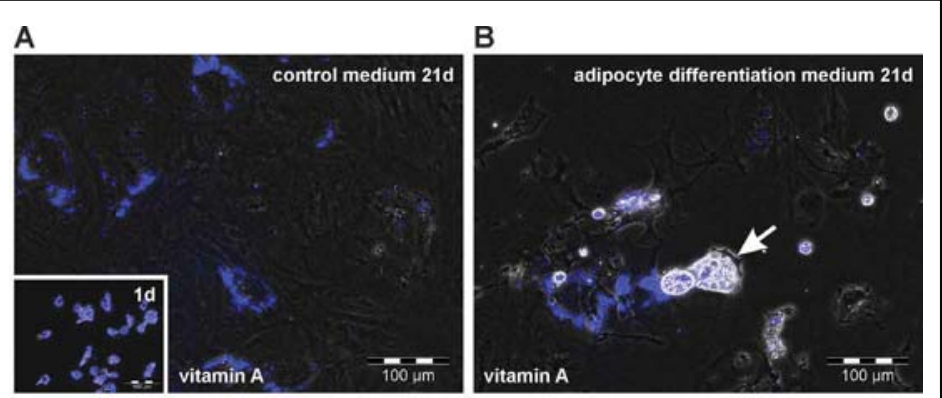

C

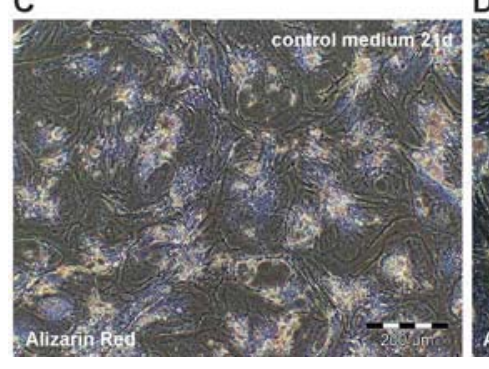

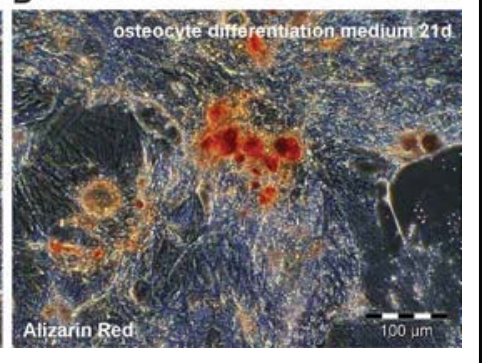

Adipocytes with large lipid droplets without retinoids as determined by UV excitation (blue) were indicated (white arrow) [n = 3]. The deposition of calcium minerals (red) by culture-activated hepatic stellate cells was investigated by Alizarin Red staining after treatment with (C) control medium or (D) osteocyte differentiation medium for 21 days [ $\mathrm{n}=3]$.

for 21 days, the synthesis of either FABP4 or osteocalcin was induced in hepatic stellate cells, whereas stellate cells that received control medium (DMEM supplemented with $10 \%$ FCS) remained negative for these proteins as investigated by immunofluorescence (Fig. 3CF). About $16.9 \%$ [n $=3$ ] of the cells exhibited FABP4 expression, whereas approximately $67.1 \%[n=4]$ of the cells were positive for osteocalcin when the diverse differentiation media were applied. The induction of FABP4 and osteocalcin expression in hepatic stellate cells was confirmed by RT-PCR (Fig. 3G,H). The vitamin A stores decreased in stellate cells with culture time compared to freshly isolated stellate cells (1d, insert) as investigated by UV light excitation of retinoids (Fig. 4A). The treatment of culture-activated hepatic stellate cells with adipocyte differentiation medium induced adipocytes with large lipid droplets, but the newly developed adipocytes displayed no retinoid fluorescence after UV excitation (Fig. 4B). The deposition of calcium minerals by hepatic stellate cell-derived osteocytes was investigated by Alizarin Red staining. Increased mineralization was only observed after application of the osteocyte differentiation medium, but not in the control (Fig. 4C,D). Thus, functional osteocytes capable to deposit minerals developed from cultured hepatic stellate cells. Treatment of hepatic stellate cells with osteocyte differentiation medium induced also the typical cell morphology of osteocytes with multiple cellular processes (Fig. 3F).

\section{Hepatic stellate cells support hematopoiesis}

One major function of MSC is their supportive effect on the maintenance and development of hematopoietic stem/progenitor cells. In order to investigate, if isolated stellate cells can fulfill this function, murine SCA1 ${ }^{+}$hematopoietic stem cells were co-cultured with hepatic stellate cells or bone marrow MSC from rats. The origin of isolated cells from different species allowed the detection of murine factors independently from rat feeder cells in the qPCR. The specificity of mouse primers was verified by comparative RT-PCR analysis of bone marrow samples from the two species. The mouse-specific primers were unable to amplify PCR products in the rat bone marrow (Fig. 5A). Amplification products from mouse primers in samples of rat feeder cells obtained by qPCR were not significantly different from the cycle 


\section{Cellular Physiology Cell Physiol Biochem 2013;31:290-304

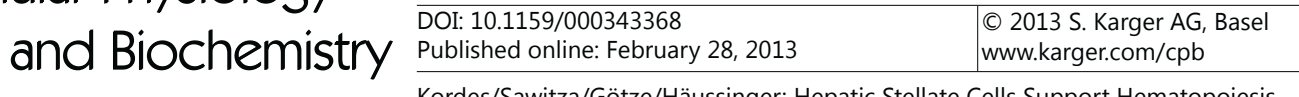

Fig. 5. Rat hepatic stellate cells support murine $\mathrm{SCA}^{+}$hematopoietic stem cells. (A) Specific mouse primer sets for the hematopoietic factors SCA1, GATA1, SLAMF1, c-kit and HPRT1 were developed, which allowed the detection of murine cells independently from rat feeder cells. These mouse primers were used for qPCR and their specificity was tested by RT-PCR in bone marrow cell lysates of mice and rats. The primers for mouse/rat HPRT1 were used as a control. (B) Isolated $\mathrm{SCA}^{+}$hematopoietic stem cells from the bone marrow of mice were cultured for 10 days without feeder cells in the presence of cytokines (IL3, IL-6 and EPO) [ $n=4]$. (C) Murine SCA $1^{+}$hematopoietic stem cells were co-cultured with rat hepatic stellate cells as feeder cells under the same conditions [n = 4]. (D) This co-culture experiment was also performed with bone marrow MSC of rats as feeder cells for murine $\mathrm{SCA} 1^{+}$hematopoietic stem cells in the presence of cytokines for 10 days [n =4]. (E) qPCR of mouse-specific SCA1 after co-culture of murine SCA $1^{+}$ hematopoietic stem cells with hepatic stellate cells or bone marrow MSC of rats as feeder cells in the presence of cytokines $\left[\mathrm{n}=4 ;{ }^{*} \mathrm{P}<0.05\right]$. Quantitative analysis of mouse-specific mRNA of (F) GATA1, (G) SLAMF1 and (H) c-kit by qPCR was performed in the same experiments [ $\left.=4 ;{ }^{*} \mathrm{P}<0.05\right]$. The lack of hematopoietic marker expression was indicated as not detectable (n.d.).

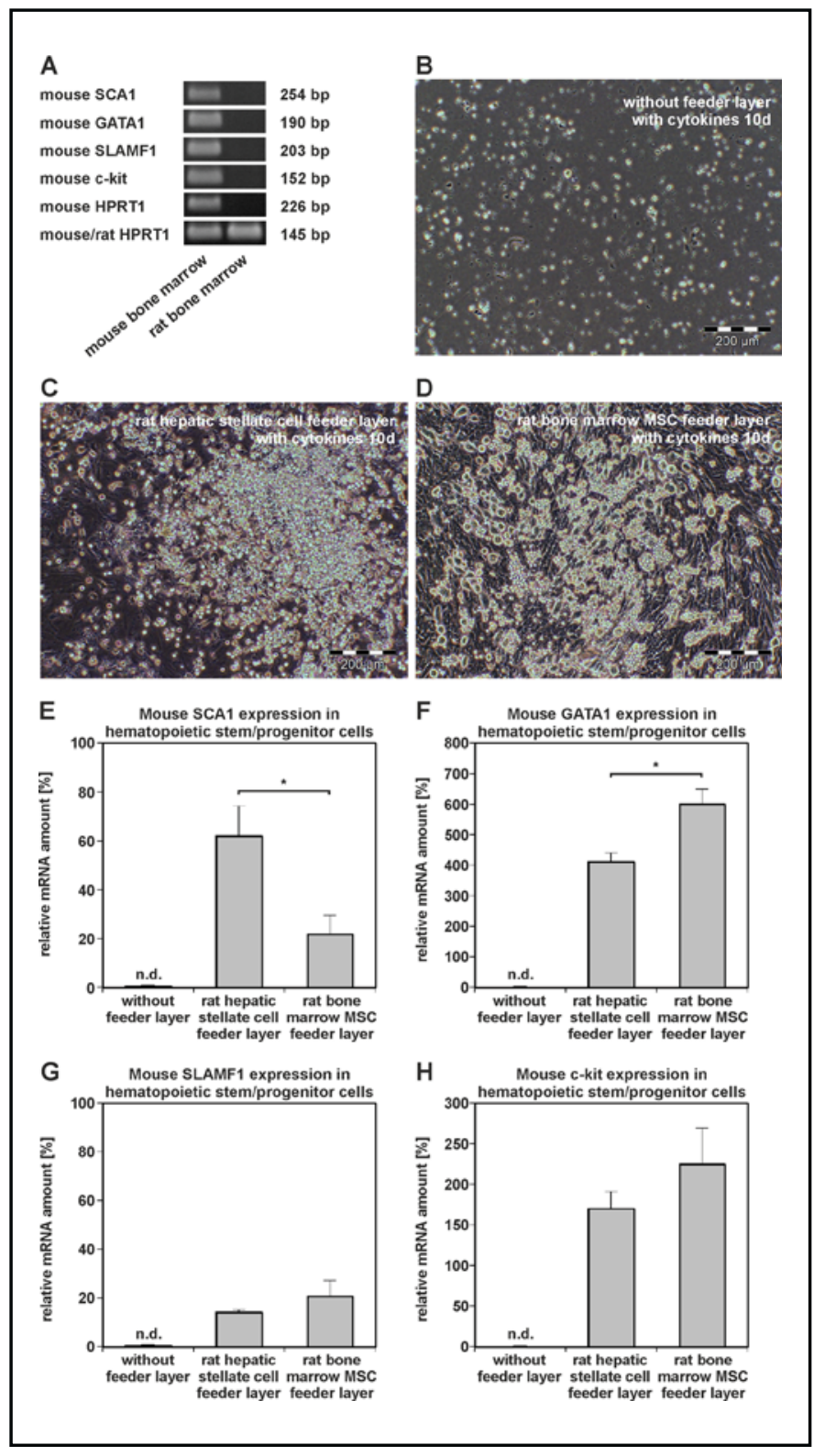

numbers measured in no template controls (NTC; not shown). SCA1 ${ }^{+}$hematopoietic stem cells were unable to form cell colonies in the absence of feeder cells even in the presence of FCS and the cytokines IL-3, IL-6 and EPO (Fig. 5B). Under these conditions the mRNA of murine SCA1, GATA1, SLAMF1 and c-kit mRNA were not detectable by qPCR after 10 days of culture (Fig. 5E-H). When, however, the murine SCA1 ${ }^{+}$hematopoietic stem cells were cultured on rat hepatic stellate cells as feeder cells, many cell colonies appeared above the stellate cell feeder layer and elevated levels of mouse GATA1 and mouse c-kit mRNA were measured by qPCR (Fig. 5C,F,H). A similar observation was made when bone marrow MSC from rats were used as feeder cells (Fig. 5D,F,H), but the expression of mouse SCA1 was significantly lower compared to the stellate cell feeder layers, whereas mouse GATA1 expression was significantly higher in murine progenitor cells on MSC feeder layers (Fig. 5E,F). Mouse SLAMF1 expression in murine hematopoietic cells was not significantly changed by different feeder cells in the presence of cytokines (Fig. 5G). 
Fig. 6. Among major liver cell types only hepatic stellate cells significantly support the maintenance of murine SCA $1^{+}$ hematopoietic stem cells. Liver cell types such as (A) stellate cells, (B) parenchymal cells (PC), (C) sinusoidal endothelial cells (SEC) and (D) Kupffer cells (KC) were used as feeder cells for murine $\mathrm{SCA} 1^{+}$hematopoietic stem cells for 10 days without addition of hematopoietic cytokines. The identity of isolated liver cell types was verified by immunofluorescence (red) of keratin 18 (PC), rat endothelial antigen 1 (Reca1; SEC) and CD163 (KC) before the co-cultures with murine SCA1 ${ }^{+}$hematopoietic cells were initiated (inserts). Mousespecific mRNAs of (E) HPRT1 and (F) SCA1 were analyzed in the co-cultures of murine SCA $1^{+}$ hematopoietic stem cells with different rat liver cell types after 10 days by qPCR $\left[\mathrm{n}=3 ;{ }^{*} \mathrm{P}<0.05\right]$. Mouse-specific SCA1 mRNA amounts were normalized on murine HPRT1 expression.

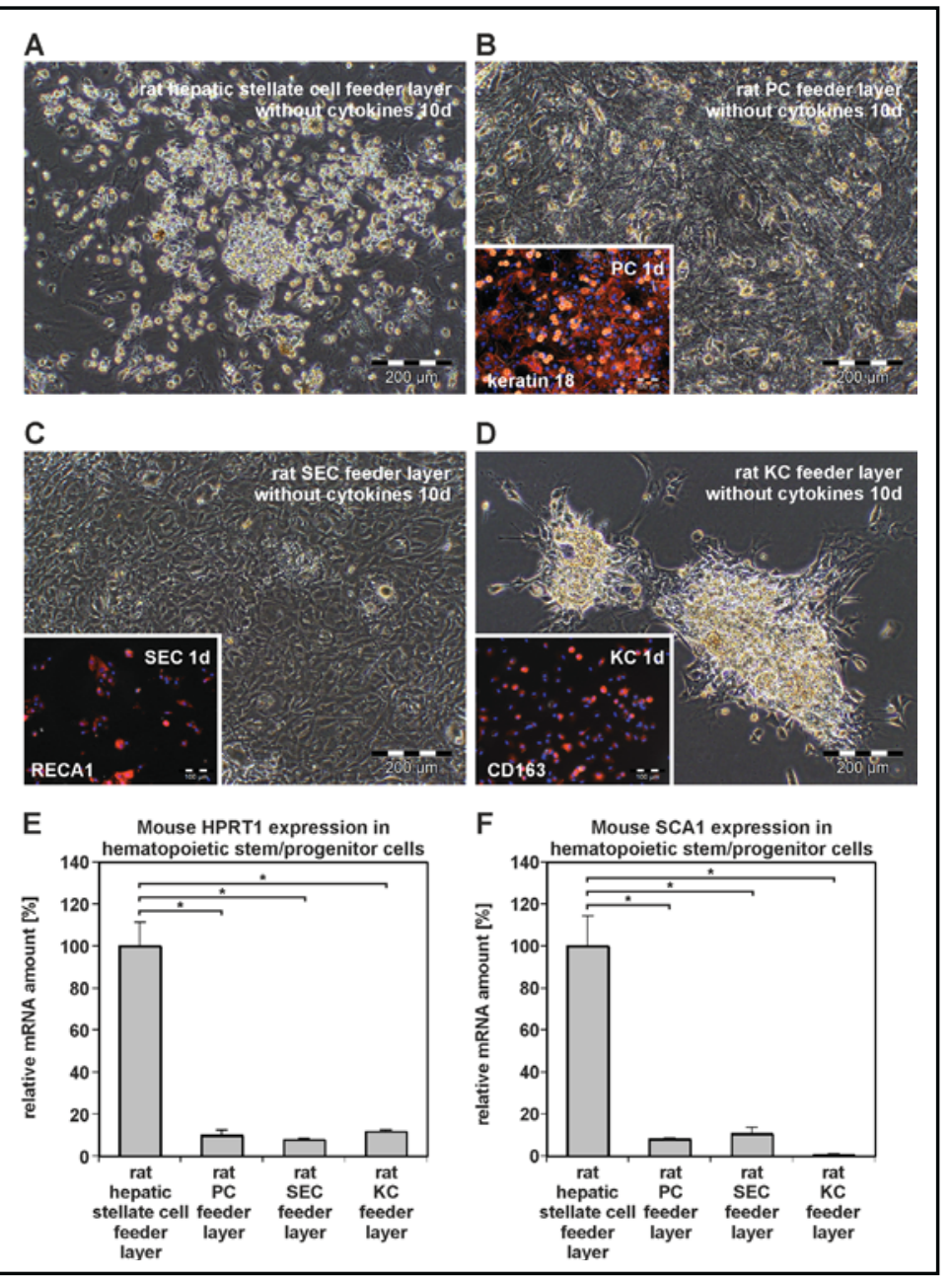

Among major liver cell types such as hepatic stellate cells, parenchymal cells (PC), sinusoidal endothelial cells (SEC) and Kupffer cells (KC) only stellate cells were able to maintain murine $\mathrm{SCA} 1^{+}$hematopoietic stem/progenitor cells during co-culture. Colony formation as well as maintenance of mouse HPRT1 and mouse SCA1 expression was significantly higher on hepatic stellate cell feeder layers compared to other rat liver cell types as determined by microscopic analysis and qPCR in the absence of cytokines after 10 days of co-culture (Fig. 6A-F). The identity of PC, SEC and KC was verified by immunofluorescence of cell type-specific markers such as keratin 18, RECA1 and CD163 (Fig. 6B-D, inserts). These primary cultures of different cell types contained only few stellate cells as investigated by GFAP immunofluorescence (not shown). The presence of $\mathrm{GFAP}^{+}$stellate cells may explain the persistence of low mouse HPRT1 and SCA1 mRNA amounts in experiments with PC, SEC and KC as feeder cells (Fig. 6E,F). Cell aggregates, which appeared in cultures with KC as feeder layers (Fig. 6D), were mainly formed by rat KC. This was investigated during coculture of $\mathrm{eGFP}^{+} \mathrm{KC}$ from rats with $\mathrm{SCA1}^{+}$hematopoietic stem cells from wild type mice by eGFP fluorescence analysis (not shown).

It was also tested, if hepatic stellate cells can principally contribute to blood cell formation through differentiation into hematopoietic cell lineages. This was investigated by transplantation of freshly isolated $\mathrm{eGFP}^{+}$hepatic stellate cells (Fig. 7A) into lethally irradiated wild type rats. Prior to this, the reconstitution of blood formation after lethal irradiation was established with unsorted $\mathrm{eGFP}^{+}$bone marrow cells (Fig. 7B), which are known to contain hematopoietic stem cells. Hematopoietic stem cells have the potential to differentiate into blood cell lineages. Bone marrow cells from $\mathrm{eGFP}^{+}$rats were transplanted 
Fig. 7. Transplantation of $\mathrm{eGFP}^{+}$ bone marrow cells and hepatic stellate cells of rats into lethally irradiated wild type rats. (A) Analysis of eGFP fluorescence (green) and characteristic lipid vesicles containing vitamin A/retinoids (blue) in freshly isolated rat hepatic stellate cells from $\mathrm{eGFP}^{+}$ Wistar rats by excitation with blue $(470-490 \mathrm{~nm})$ or UV light (330-385 nm), respectively. eGFP fluorescence (green) of bone marrow cells from $\mathrm{eGFP}^{+}$Wistar rats. (C) Survival curves of wild type rats (indicated by the body weight) after irradiation with 9 Gy at day 0. Bone marrow cells from $\mathrm{eGFP}^{+}$rats were
B

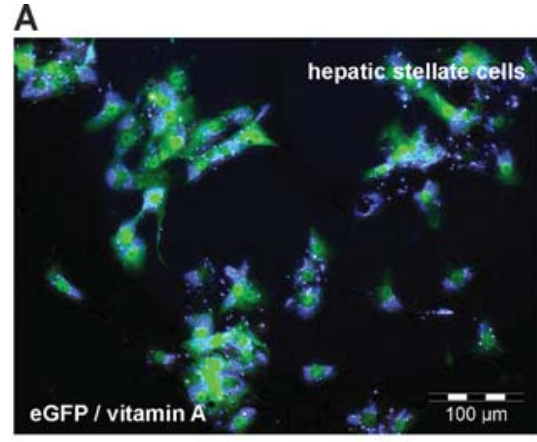

C
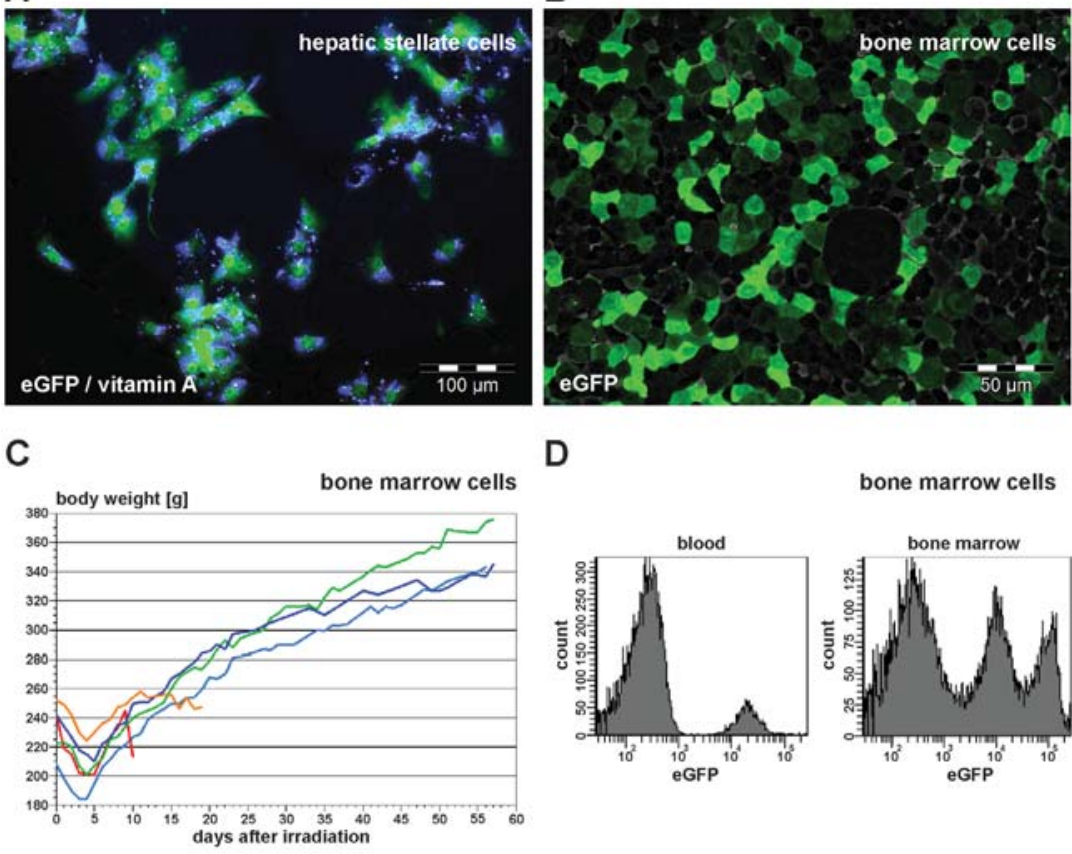

D

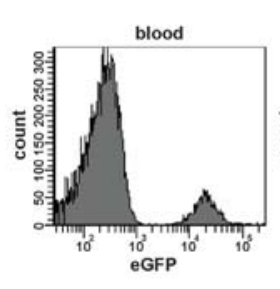

bone marrow cells
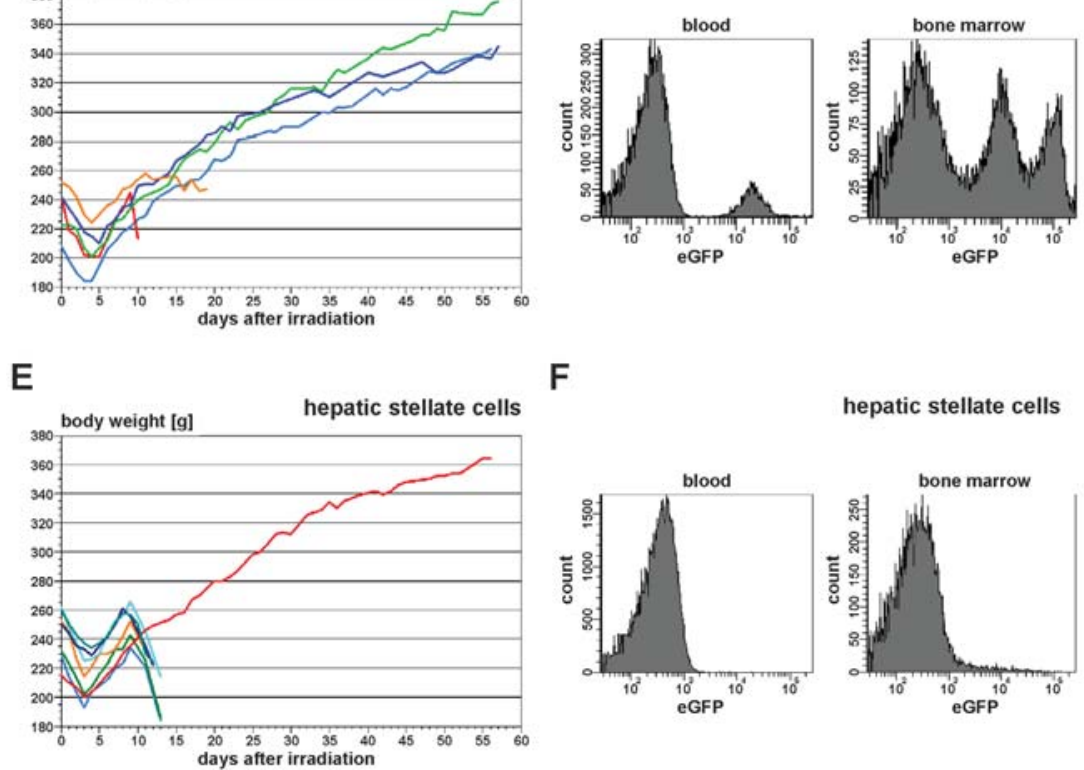

$\mathbf{F}$

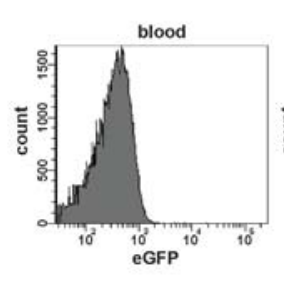

hepatic stellate cells

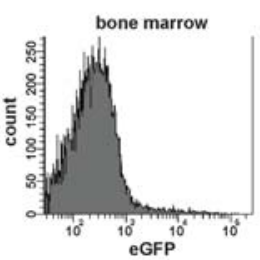

transplanted via tail vein injection immediately after irradiation [ $\mathrm{n}=5]$. (D) eGFP fluorescence was analyzed by flow cytometry (excitation $488 \mathrm{~nm}$, emission $530 / 30 \mathrm{~nm}$ ) in cells from blood and bone marrow 8 weeks after lethal irradiation of rats, which received unsorted eGFP+ bone marrow cells $[n=3]$. (E) Freshly isolated hepatic stellate cells were transplanted into lethally irradiated rats via tail vein injection [n $=7]$. (F) Flow cytometry analysis of eGFP fluorescence in blood and bone marrow cells of one animal that survived lethal irradiation after transplantation of $\mathrm{eGFP}^{+}$hepatic stellate cells.

into 5 lethally irradiated wild type rats and 3 of the host animals survived (Fig. 7C). The eGFP fluorescence was detected by flow cytometry in cells of the blood and bone marrow 8 weeks after lethal irradiation, indicating that the blood formation was successfully reconstituted by transplanted $\mathrm{eGFP}^{+}$bone marrow cells (Fig. 7D). Freshly isolated $\mathrm{GFP}^{+}$hepatic stellate cells were transplanted into 7 lethally irradiated rats. Only one animal survived as indicated by the steady increase of its body weight (Fig. 7E; red line). Although this animal survived, its blood and bone marrow displayed no eGFP fluorescence after transplantation of eGFP ${ }^{+}$ hepatic stellate cells as investigated by flow cytometry (Fig. 7F). Apparently, transplanted hepatic stellate cells did not differentiate into blood cell lineages in these experiments. Therefore, hepatic stellate cells possibly exerted their supportive effects on hematopoiesis in the co-culture system (Fig. 5) through the release of hematopoietic cytokines. The mRNA of IL-3, IL-6, EPO, macrophage colony-stimulating factor (M-CSF), granulocyte macrophage colony-stimulating factor (GM-CSF) and granulocyte colony-stimulating factor (G-CSF) were congruently found in hepatic stellate cells and bone marrow MSC by qPCR (Fig. 8). The 
Fig. 8. qPCR analysis of cytokines involved in blood formation in samples of freshly isolated and cultured hepatic stellate cells as well as bone marrow MSC of rats. Hepatic stellate cells were cultured for 1 (1d) and 7 days (7d) before the mRNA samples were collected [ $n=4]$. Bone marrow MSC were used after depletion of lineage committed cells and cultured for at least 14 days prior to analysis [ $n=3]$. Significant differences between quiescent and culture-activated stellate cells as well as bone marrow MSC are indicated [ $\left.{ }^{*} \mathrm{P}<0.05\right]$. The mRNA amounts of cytokines measured in bone marrow MSC were set to $100 \%$.

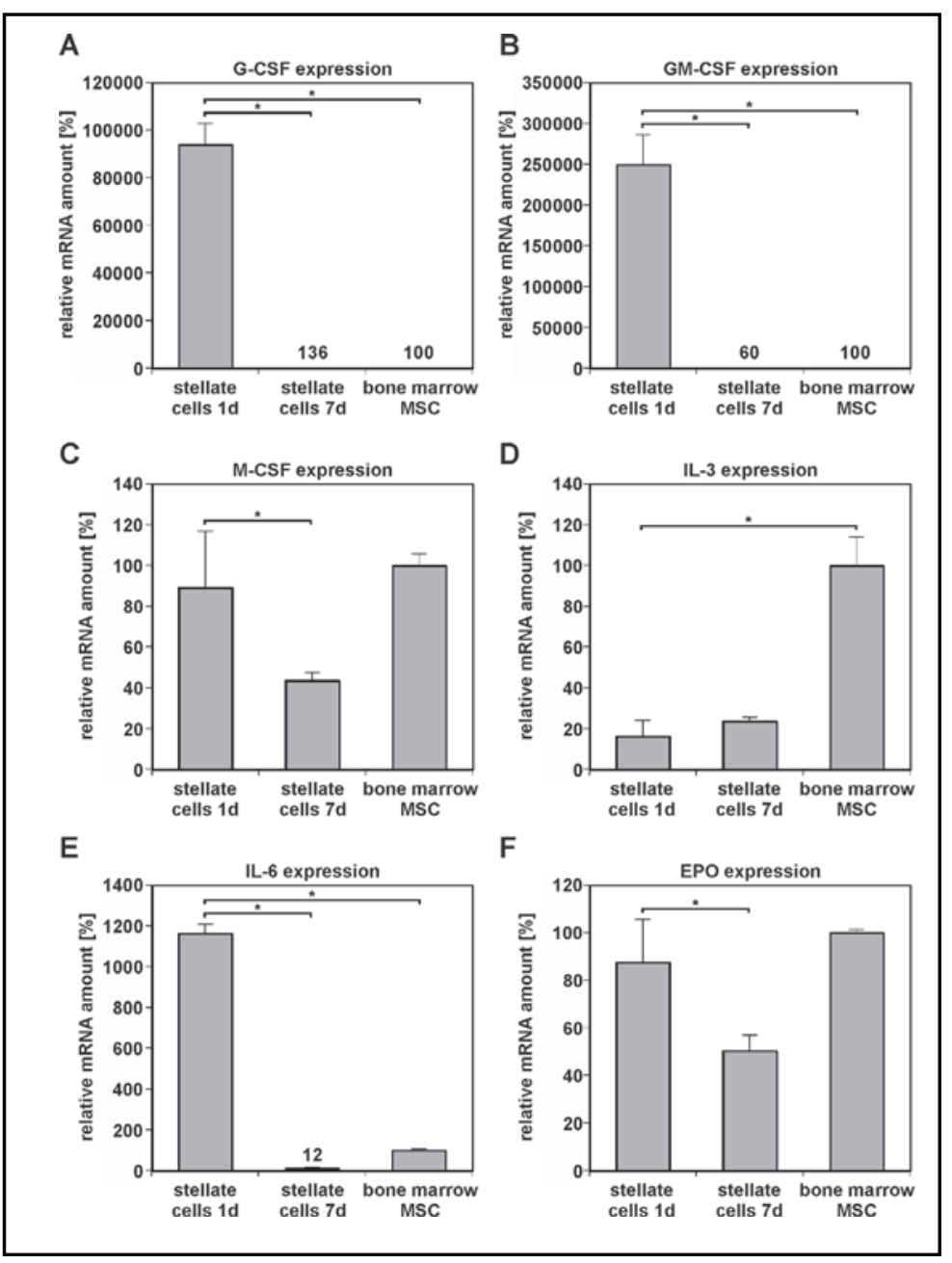

expression of G-CSF, GM-CSF and IL-6 was high in freshly isolated stellate cells and declined during their activation in culture (Fig. 8).

\section{Discussion}

Hepatic stellate cells are supposed to be involved in liver fibrogenesis after their activation, but little is known about their function in normal liver. However, recent data suggest that stellate cells have stem cell characteristics $[9,10]$, but their relation to known adult stem cell types remained unclear. As shown in the present study, hepatic stellate cells represent not yet recognized MSC of the liver. This is evidenced by (i) their expression of MSC markers, (ii) their ability to differentiate into adipocytes or osteocytes and (iii) their supportive effects on hematopoiesis.

Desmin $^{+}$stellate cells are typical pericytes and can be found in close contact to developing hematopoietic progenitor cells in the fetal liver [7]. A differentiation of hepatic stellate cells into blood cell lineages was not observed after their transplantation into lethally irradiated rats, but they supported the maintenance, expansion and further development of SCA1 $1^{+}$hematopoietic stem cells. This occurs probably through the release of cytokines such as IL-3, IL-6, CSFs and EPO, which are essential for blood cell formation [16]. EPO for example is known to be produced by hepatic stellate cells and was recently described to be released also by MSC in response to PDGF-BB treatment $[17,18]$. Thus, stellate cells can 


\section{Cellular Physiology and Biochemistry}

Cell Physiol Biochem 2013;31:290-304

DOI: $10.1159 / 000343368$

Published online: February 28, 2013

C) 2013 S. Karger AG, Basel

www.karger.com/cpb

fulfill one important function of bone marrow MSC, namely the support of hematopoiesis. In contrast to this, other major liver cell types such as PC, SEC and KC were unable to effectively maintain hematopoietic stem cells. Hepatic stellate cells seem to be more efficient than bone marrow MSC in maintaining the expression of SCA1 in hematopoietic stem cells, which characterizes an early developmental state $[11,19]$. Early hematopoietic stem/progenitor cells can preserve their SCA1 expression in the presence of retinoids (e.g. all-trans retinoic acid) [19], which are released into the culture medium during activation of hepatic stellate cells. Therefore, stellate cell-derived retinoids could be responsible for the elevated SCA1 mRNA levels in murine hematopoietic stem cells in our study, whereas the differentiation marker GATA1 was lower in the presence of hepatic stellate cells compared to bone marrow MSC.

Stellate cells maintain their characteristics in a microenvironment, comprising of stromal cell-derived factor 1-releasing endothelial cells, WNT and notch ligand-producing hepatocytes as well as a basement membrane-like matrix in the space of Disse [20]. This niche of stellate cells displays similarities to the perivascular hematopoietic stem cell niche in the bone marrow and may favor homing of migrating hematopoietic stem/progenitor cells and extramedullary hematopoiesis in the liver. Stellate cells are closely associated with nerve fibers of the peripheral nervous system as reported for bone marrow MSC and can integrate signals from the sympathetic nervous system [3, 4, 21-23]. Furthermore, bone marrow MSC and hepatic stellate cells can be activated by external stimuli such as hypoxia and release cytokines like vascular endothelial growth factor, hepatocyte growth factor, angiopoietins and insulin-like growth factors, in order to modulate the behavior of other cell types such as endothelial cells [24-28]. In addition to these modulatory effects, stellate cells can also differentiate into adipocytes and osteocytes in vitro as demonstrated in this study, which are additional functional requirements for their classification as MSC and further underline the stem cell character of stellate cells. This developmental potential is in agreement with a recent study on the human hepatic stellate cell line LX-2 [29].

Typical MSC markers such as nestin, CD29 and PDGFR $\beta[30,31]$ are expressed by quiescent hepatic stellate cells at a low level, but their synthesis increases during activation of stellate cells in culture. This may explain why stellate cells were overlooked as liverresident MSC in the past. The presence of the astroglial marker GFAP at the protein level and the storage of retinoids in lipid vesicles is normally not observed in isolated bone marrow MSC and may also impede the recognition of hepatic stellate cells as MSC. Similar to hepatic stellate cells, the undifferentiated state of bone marrow MSC can be preserved by retinoids [32]. The cell surface protein CD133 is expressed by hematopoietic stem/progenitor cells, but also occurs in stellate cells and bone marrow MSC [9, 33, 34], showing decreased expression in both cells with culture [20,33,34].

In conclusion, hepatic stellate cells display the expression pattern and exert functions of bone marrow MSC and are, therefore, liver-resident MSC. This finding does not contradict the prevailing view about a contribution of stellate cells to fibrosis, since MSC are supposed to be involved in fibrogenesis in chronic diseases [35]. However, attempts to eliminate activated hepatic stellate cells for treatment of liver fibrosis have to be reconsidered in view of potential side-effects on hematopoiesis.

\section{Abbreviations}

MSC (mesenchymal stem cells); SCA1 (stem cell antigen 1); GATA1 (GATA binding protein 1); DMEM (Dulbecco's Modified Eagle Medium); FCS (fetal calf serum); SEC (sinusoidal endothelial cells); KC (Kupffer cells); PC (parenchymal cells); IL (interleukin); EPO (erythropoietin); FABP4 (fatty acid binding protein 4 ); $\alpha$-SMA ( $\alpha$-smooth muscle actin); GFAP (glial fibrillary acidic protein); RECA1 (rat endothelial antigen 1); PDFGR $\beta$ /PDGF-BB (platelet-derived growth factor receptor- $\beta /$-BB); DAPI (4',6-diamidino-2-phenylindole); GS 


\section{Cellular Physiology and Biochemistry}

Cell Physiol Biochem 2013;31:290-304

\begin{tabular}{l|l}
\hline DOI: $10.1159 / 000343368$ & (c) 2013 S. Karger AG, Basel
\end{tabular}

Publisned onine: February 28, 2013

www.karger.com/cpb

Kordes/Sawitza/Götze/Häussinger: Hepatic Stellate Cells Support Hematopoiesis

(glutamine synthetase); RT-PCR (reverse transcriptase-polymerase chain reaction); qPCR (quantitative real-time PCR); HPRT1 (hypoxanthine-guanine phosphoribosyltransferase 1); RPS6 (ribosomal protein S6); SLAMF1 (signaling lymphocytic activation molecule F1); UTR (untranslated region); NTC (no template control); eGFP (enhanced green fluorescent protein); Gy (gray); COL1 $\alpha 2$ (collagen type $1 \alpha 2$ chain); NG2 (nerve/glial antigen 2); M-CSF (macrophage colony-stimulating factor); GM-CSF (granulocyte macrophage colonystimulating factor); G-CSF (granulocyte colony-stimulating factor); LSM (laser-scanning microscope).

\section{Acknowledgements}

The authors are grateful to Claudia Rupprecht for expert technical assistance, Eiji Kobayashi for the generation of the transgenic rats and the German Research Foundation (Deutsche Forschungsgemeinschaft) for the financial support through the Collaborative Research Center 974 (SFB 974) "Communication and Systems Relevance during Liver Injury and Regeneration".

\section{References}

1 Calvi LM, Adams GB, Weibrecht KW, Weber JM, Olson DP, Knight MC, Martin RP, Schipani E, Divieti P, Bringhurst FR, Milner LA, Kronenberg HM, Scadden DT: Osteoblastic cells regulate the haematopoietic stem cell niche. Nature 2003;425:841-846.

$\longrightarrow 2$ Kiel MJ, Yilmaz OH, Iwashita T, Terhorst C, Morrison SJ: SLAM family receptors distinguish hematopoietic stem and progenitor cells and reveal endothelial niches for stem cells. Cell 2005;121:1109-1121.

- Katayama Y, Battista M, Kao W-M, Hidalgo A, Peired AJ, Thomas SA, Frenette PS: Signals from the sympathic nervous system regulate hematopoietic stem cell egress from the bone marrow. Cell 2006;124:407-421.

-4 Méndez-Ferrer S, Michurina TV, Ferraro F, Mazloom AR, Macarthur BD, Lira SA, Scadden DT, Ma'ayan A, Enikolopov GN, Frenette PS: Mesenchymal and haematopoietic stem cells form a unique bone marrow niche. Nature 2010;466:829-834.

5 Hackney JA, Charbord P, Brunk BP, Stoeckert CJ, Lemischka IR, Moore KA: A molecular profile of a hematopoietic stem cell niche. Proc Natl Acad Sci USA 2002;99:13061-13066.

6 Martin MA, Bhatia M: Analysis of the human fetal liver hematopoietic microenvironment. Stem Cells Dev 2005;14:493-504.

7 Kiassov AP, Van Eyken P, Van Pelt JF, Depla E, Fevery J, Desmet VJ, Yap SH: Desmin expressing nonhematopoietic liver cells during rat liver development: an immunohistochemical and morphometric study. Differentiation 1995;59:253-258.

8 Kubota H, Yao HL, Reid LM: Identification and characterization of vitamin A-storing cells in fetal liver: implications for functional importance of hepatic stellate cells in liver development and hematopoiesis. Stem Cells 2007;25:2339-2349.

-9 Kordes C, Sawitza I, Müller-Marbach A, Ale-Agha N, Keitel V, Klonowski-Stumpe H, Häussinger D: CD133+ hepatic stellate cells are progenitor cells. Biochem Biophys Res Commun 2007;352:410-417.

10 Kordes C, Sawitza I, Götze S, Häussinger D: Stellate cells from rat pancreas are stem cells and can contribute to liver regeneration. PLoS One 2012;7:e51878.

11 Spangrude GJ, Heimfeld S, Weissman IL: Purification and characterization of mouse hematopoietic stem cells. Science 1988;241:58-62.

$>12$ Akashi K, Traver D, Miyamoto T, Weissman IL: A clonogenic common myeloid progenitor that gives rise to all myeloid lineages. Nature 2000;404:193-197.

13 Hendriks HFJ, Verhoofstad WA, Brouwer A, de Leeuw AM, Knook DL: Perisinusoidal fat-storing cells are the main vitamin A storage sites in rat liver. Exp Cell Res 1985;160:138-149.

14 Knook DL, Sleyster EC: Separation of Kupffer and endothelial cells of the rat liver by centrifugal elutriation. Exp Cell Res 1976;99:444-449. 


\section{Cellular Physiology and Biochemistry}

Cell Physiol Biochem 2013;31:290-304

DOI: $10.1159 / 000343368$

Published online: February 28, 2013

C 2013 S. Karger AG, Basel

www.karger.com/cpb

Kordes/Sawitza/Götze/Häussinger: Hepatic Stellate Cells Support Hematopoiesis

15 Berry MN, Friend DS: High-yield preparation of isolated rat liver parenchymal cells. A biochemical and fine structural study. J Cell Biol 1969;43:506-520.

16 Metcalf D: Hematopoietic cytokines. Blood 2008;111:485-491.

17 Maxwell PH, Ferguson DJ, Osmond MK, Pugh CW, Heryet A, Doe BG, Johnson MH, Ratcliffe PJ: Expression of a homologously recombined erythopoietin-SV40 T antigen fusion gene in mouse liver: evidence for erythropoietin production by Ito cells. Blood 1994;84:1823-1830.

-18 Xue Y, Lim S, Yang Y, Wang Z, Jensen LD, Hedlund EM, Andersson P, Sasahara M, Larsson O, Galter D, Cao R, Hosaka K, Cao Y: PDGF-BB modulates hematopoiesis and tumor angiogenesis by inducing erythropoietin production in stromal cells. Nat Med 2011;18:100-110.

19 Purton LE, Bernstein ID, Collins SJ: All-trans retinoic acid delays the differentiation of primitive hematopoietic precursors (lin-c-kit+Sca-1+) while enhancing the terminal maturation of committed granulocyte/monocyte progenitors. Blood 1999;94:483-495.

20 Sawitza I, Kordes C, Reister S, Häussinger D: The niche of stellate cells within rat liver. Hepatology 2009;50:1617-1624.

-21 Athari A, Hänecke K, Jungermann K: Prostaglandin F2alpha and D2 release from primary Ito cell cultures after stimulation with noradrenaline and ATP but not adenosine. Hepatology 1994;20:142-148.

-22 vom Dahl S, Bode JG, Reinehr R, Mönnighoff I, Kubitz R, Häussinger D: Release of osmolytes from perfused rat liver on perivascular nerve stimulation: alpha-adrenergic control of osmolyte efflux from parenchymal and nonparenchymal liver cells. Hepatology 1999;1:195-204.

23 McCuskey RS: Anatomy of efferent hepatic nerves. Anat Rec A Discov Mol Cell Evol Biol 2004;280:821-826.

-24 Ramadori G, Neubauer K, Odenthal M, Nakamura T, Knittel T, Schwögler S, Meyer zum Büschenfelde KH: The gene of hepatocyte growth factor is expressed in fat-storing cells of rat liver and is downregulated during cell growth and by transforming growth factor-beta. Biochem Biophys Res Commun 1992;183:739742.

-25 Aleffi S, Petrai I, Bertolani C, Parola M, Colombatto S, Novo E, Vizzutti F, Anania FA, Milani S, Rombouts K, Laffi G, Pinzani M, Marra F: Upregulation of proinflammatory and proangiogenic cytokines by leptin in human hepatic stellate cells. Hepatology 2005;42:1339-1348.

-26 Crisostomo PR, Wang Y, Markel TA, Wang M, Lahm T, Meldrum DR: Human mesenchymal stem cells stimulated by TNF-alpha, LPS, or hypoxia produce growth factors by an NF kappa B- but not JNKdependent mechanism. Am J Physiol Cell Physiol 2008;294:C675-682.

27 Taura K, De Minicis S, Seki E, Hatano E, Iwaisako K, Osterreicher CH, Kodama Y, Miura K, Ikai I, Uemoto S, Brenner DA: Hepatic stellate cells secrete angiopoietin 1 that induces angiogenesis in liver fibrosis. Gastroenterology 2008;135:1729-1738.

28 Torimura T, Ueno T, Kin M, Harada R, Taniguchi E, Nakamura T, Sakata R, Hashimoto O, Sakamoto M, Kumashiro R, Sata M, Nakashima 0, Yano H, Kojiro M: Overexpression of angiopoietin-1 and angiopoietin-2 in hepatocellular carcinoma. J Hepatol 2004;40:799-807.

29 Castilho-Fernandes A, de Almeida DC, Fontes AM, Melo FU, Picanço-Castro V, Freitas MC, Orellana MD, Palma PV, Hackett PB, Friedman SL, Covas DT: Human hepatic stellate cell line (LX-2) exhibits characteristics of bone marrow-derived mesenchymal stem cells. Exp Mol Pathol 2011;91:664-672.

-30 Crisan M, Yap S, Casteilla L, Chen CW, Corselli M, Park TS, Andriolo G, Sun B, Zheng B, Zhang L, Norotte C, Teng PN, Traas J, Schugar R, Deasy BM, Badylak S, Buhring HJ, Giacobino JP, Lazzari L, Huard J, Péault B: A perivascular origin for mesenchymal stem cells in multiple human organs. Cell Stem Cell 2008;3:301-313.

-31 Chamberlain G, Fox J, Ashton B, Middleton J: Concise review: mesenchymal stem cells: their phenotype, differentiation capacity, immunological features, and potential for homing. Stem Cells 2007;25:2739-2749.

-32 de Hemptinne I, Vermeiren C, Maloteaux JM, Hermans E: Induction of glial glutamate transporters in adult mesenchymal stem cells. J Neurochem 2004;91:155-166.

-33 Tondreau T, Meuleman N, Delforge A, Dejeneffe M, Leroy R, Massy M, Mortier C, Bron D, Lagneaux L: Mesenchymal stem cells derived from CD133-positive cells in mobilized peripheral blood and cord blood: proliferation, Oct4 expression, and plasticity. Stem Cells 2005;23:1105-1112.

-34 Pozzobon M, Piccoli M, Ditadi A, Bollini S, Destro R, André-Schmutz I, Masiero L, Lenzini E, Zanesco L, Petrelli L, Cavazzana-Calvo M, Gazzola MV, De Coppi P: Mesenchymal stromal cells can be derived from bone marrow CD133+ cells: implications for therapy. Stem Cells Dev 2009;18:497-510.

-35 Lepperdinger G: Inflammation and mesenchymal stem cell aging. Curr Opin Immunol 2011;23:518-524. 